\title{
Practice and experience in achieving a high proportion of renewable energy in Germany
}

\author{
Wei Yuan ${ }^{1, *}$, Caixia Wang ${ }^{1}$, Xiaoning Ye ${ }^{1}$, Qionghui $\mathrm{Li}^{1}$, Liang $\mathrm{Xu}^{2}$, Ziqian $\mathrm{Li}^{1}$, and Zhiyong Shi ${ }^{1}$ \\ ${ }^{1}$ Department of New Energy and Energy Statistics, State Grid Energy Research Institute Company LTD, Beijing, China \\ ${ }^{2}$ Beijing Power Exchange Center, Beijing, China
}

\begin{abstract}
The German federal government has set very high targets for renewable energy. In recent years, Germany's renewable energy has developed rapidly. Germany leads the world in energy transformation, with wind and solar generating capacity accounting for nearly half. Germany's experience and practice in developing renewable energy are worthy of our country's reference. In this paper, the development status of renewable energy and power grid in Germany is introduced. And this paper mainly analyzes Germany's experience and practice in achieving a high proportion of new energy access in 2019.
\end{abstract}

\section{Introduction}

Germany has a surplus of generating capacity. What's more, in Germany, the proportion of new energy installation is large, and the proportion of flexible adjustment power supply is high, and the system load is relatively stable. According to the annual data of German electricity production in 2019, new energy generation accounts for more than $30 \%$ of total electricity consumption in Germany for the first time.

\section{Development status of renewable energy and power grid in Germany}

\subsection{Status of power supply and power consumption}

By the end of 2019, the total installed power capacity of Germany is $220.41 \mathrm{GW}, 2.5$ times the maximum load (88.18 GW) in 2019 [1]. As shown in Fig.1, the capacity of flexible adjustment power supply (pump storage 9.81 $\mathrm{GW}$, gas $29.85 \mathrm{GW}$, oil $4.36 \mathrm{GW}$ ) is $44.02 \mathrm{GW}$, accounting for $20 \%$ of the total installed capacity. The installed capacity of coal-fired units is $43.87 \mathrm{GW}$, accounting for $20 \%$ of the total installed capacity. The installed capacity of wind power is $60.87 \mathrm{GW}$, accounting for $27.6 \%$ of the total installed capacity. The installed capacity of solar power is $49.17 \mathrm{GW}$, accounting for $22.3 \%$ of the total installed capacity. What's more, the installed capacity of nuclear power, biomass and hydropower is $9.52 \mathrm{GW}, 8.18 \mathrm{GW}$ and 4.78 GW respectively. In terms of power supply structure, the total installed capacity of renewable energy accounts for $55.8 \%$ of the total installed capacity. And the installed capacity of new energy accounts for nearly half.

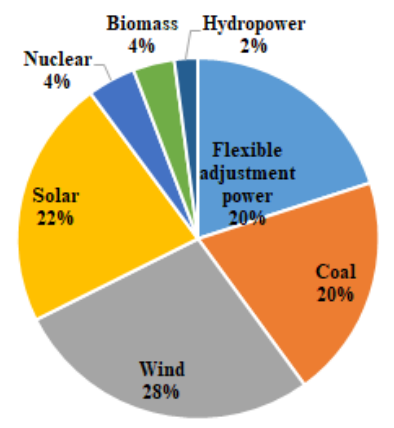

Fig. 1. Power Supply Structure of Germany in 2019.

In 2019 , the total generating electricity of all power supply in Germany is $605 \mathrm{TWh}$ [2]. As shown in Fig.2, the generating electricity of wind power is $126 \mathrm{TWh}$, accounting for $20.8 \%$ of the total power generation. The generating electricity of solar power is $47 \mathrm{TWh}$, accounting for $7.8 \%$ of the total power generation. In terms of electricity generation, the electricity of fossil power accounts for $47.6 \%$ and that of renewable energy accounts for $40.2 \%$ of the total electricity generation in Germany.

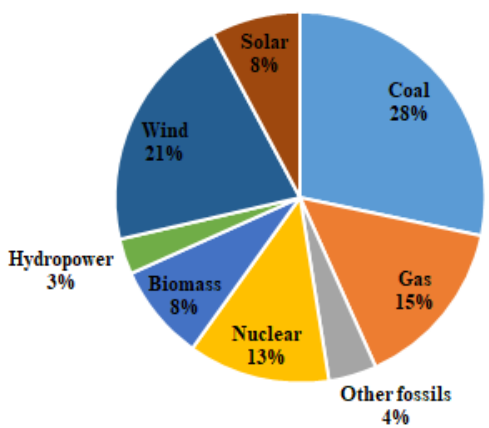

Fig. 2. Electricity Structure of Germany in 2019.

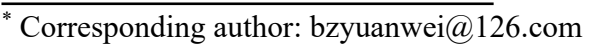




\subsection{Status of power grid}

The distribution network in Germany has developed rapidly. By the end of 2019, Germany has four transmission companies, including 50Hertz, Amprion, Tennet and TransnetBW, and nearly 900 distribution companies. In Germany, $90 \%$ capacity of renewable energy is connected to the distribution network and all the capacity of solar power is connected to the distribution network. As shown in Table 1, by the end of 2017, the length of transmission lines is 1.845 million $\mathrm{km}$, and in terms of line length, $98 \%$ of transmission lines in Germany belong to distribution companies.

Table 1. Power grid structure of Germany in 2017.

\begin{tabular}{|c|c|c|c|}
\hline & $\begin{array}{c}\text { Transmission } \\
\text { Company }\end{array}$ & $\begin{array}{c}\text { Distribution } \\
\text { Company }\end{array}$ & Total \\
\hline $\begin{array}{c}\text { Length of } \\
\text { transmission } \\
\text { lines } \\
\text { (million } \\
\mathrm{km} \text { ) }\end{array}$ & 0.0375 & 1.808 & 1.8455 \\
\hline $\begin{array}{c}\text { Number of } \\
\text { consumers }\end{array}$ & 577 & $50,467,615$ & $50,468,192$ \\
\hline
\end{tabular}

The degree of the interconnection of the domestic power grid in Germany and its long-distance transmission capacity have been constantly improved. As shown in Fig.3, by building the ultra-high voltage grid, the generating electricity of wind power in the northern can be sent to load centres in the south and west of Germany.

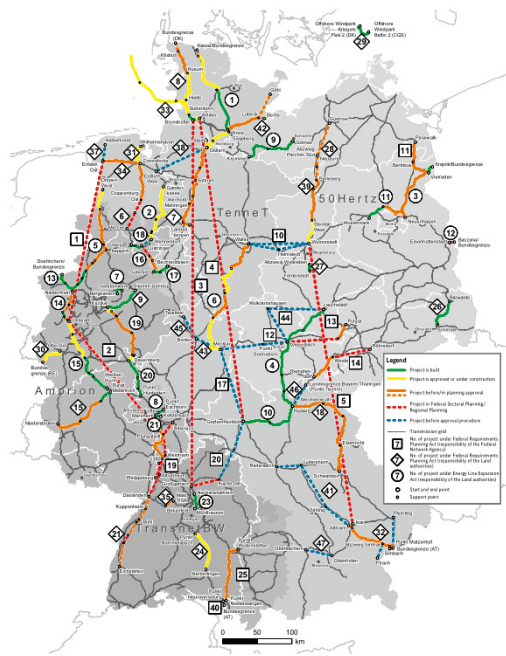

Fig. 3. Projects under the Energy Line Expansion Act and the Federal Requirements Planning Act [3].

The German power grid is highly interconnected with neighbouring countries. The power grid of Germany is part of the European Transmission Union and the hub of the European unified grid. As shown in Fig.4, Germany, Sweden, France, Luxembourg, Czech Republic, Denmark, Netherlands, Poland, Austria and Switzerland have realized the interconnection of power grid through transnational contact lines of $220 \mathrm{kV}$ and above. And the power transactions among these countries have been conducted. In 2019, the total outward electricity of
Germany is 61.265 TWh, with the total incoming electricity being $27.5 \mathrm{TWh}$. And the net outward electricity is $33.765 \mathrm{TWh}$. The electricity is mainly exported to Poland, Austria, Switzerland and the Netherlands, and mainly imported from France.

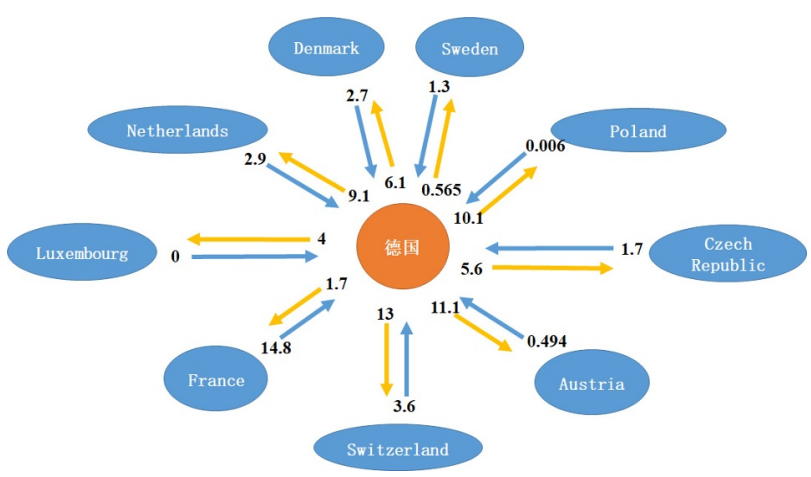

Fig. 4. Electricity Exchange between Germany and Neighbouring Countries in 2019 (TWh).

\section{Analysis of influencing factors for realizing high proportion of new energy}

\subsection{Analysis of the distribution of the output of new energy in 2019}

The capacity of new energy in Germany is $110 \mathrm{GW}$. As shown in Fig.5, the total output level of new energy is lower than $50 \mathrm{GW}$ in most time periods and is always more than 0 . Therefore, on a year-round, the range of the total output level of new energy in Germany is from 0 to $50 \mathrm{GW}$.

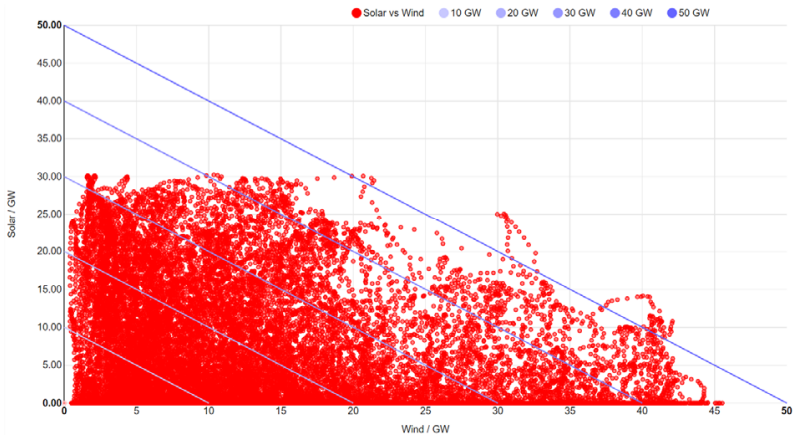

Fig. 5. Distribution of the Output of New Energy in 2019 [1].

\subsection{Analysis of the typical operation curve}

The high proportion operation of new energy in Germany has a great relationship with the participation of flexible power supply and the outward of electricity to abroad. As shown in Fig.6, at about 2:15 am on February 27 in 2019, the load is at the peak time with $67.42 \mathrm{GW}$, and the output level of wind is $2.83 \mathrm{GW}$, and the output level of solar power is 0. At around 9:00 a.m. on March 3 in 2019 , the load is at the valley time with $40.5 \mathrm{GW}$, and the output level of wind reaches $32.1 \mathrm{GW}$, and the output level of solar power is 0 .

In the whole process, the nuclear power operates to satisfy the base load, with the maximum output $9.36 \mathrm{GW}$ 
and the minimum output $7.98 \mathrm{GW}$, basically not participating in peak regulation. Coal, gas and hydropower are adjusted in line with the load and wind power in real time. The output level in peak time is 40.25 GW, and the output level in valley time is reduced to $12.56 \mathrm{GW}$. At the same time, the pumped storage unit is started to operate with a pumping power of $3.75 \mathrm{GW}$, making room for wind power. In addition, the outward power level increases in the valley time, with net imported power of $4.02 \mathrm{GW}$ during the peak period and net exported power of $14.12 \mathrm{GW}$ during the valley time. The transnational contact line plays an important role in promoting the consumption of wind power during the valley time.

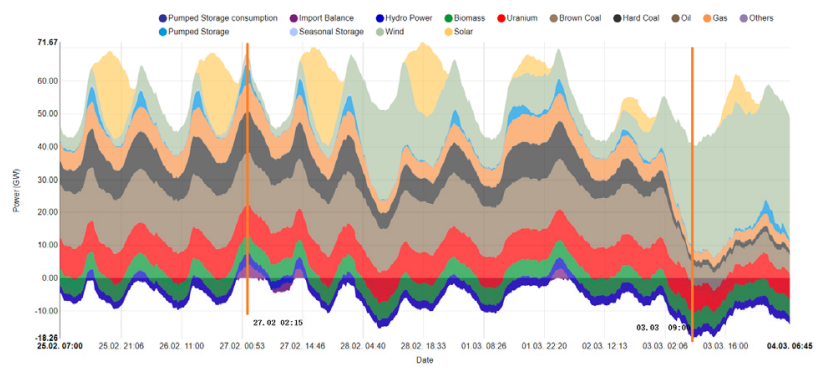

Fig. 6. Operation Curve of Power System of Germany from February 25 to March 4 in 2019 [1].

The output level, variation range and contribution of each type of power supply between peak time and valley time are shown in Table 2.

Table 2. Output level, variation range and contribution of each type of power supply.

\begin{tabular}{|c|c|c|c|c|}
\hline Type & $\begin{array}{c}\text { Peak } \\
\text { Time(G } \\
\mathbf{W})\end{array}$ & $\begin{array}{c}\text { Valley } \\
\text { Time(G } \\
\mathbf{W})\end{array}$ & $\begin{array}{c}\text { Variatio } \\
\mathbf{n} \\
\text { Range(G } \\
\mathbf{W})\end{array}$ & $\begin{array}{c}\text { Contributio } \\
\mathbf{n ( \% )}\end{array}$ \\
\hline Coal & 28.43 & 7.55 & -20.88 & 37.4 \\
\hline Gas & 8.21 & 2.46 & -5.75 & 10.3 \\
\hline Oil & 0.18 & 0.18 & 0 & 0 \\
\hline $\begin{array}{c}\text { Hydropo } \\
\text { wer }\end{array}$ & 3.61 & 2.55 & -1.06 & 1.9 \\
\hline $\begin{array}{c}\text { Nuclear } \\
\text { Biomass }\end{array}$ & 9.36 & 7.98 & -1.38 & 2.5 \\
\hline $\begin{array}{c}\text { Pumped } \\
\text { storage }\end{array}$ & 4.86 & -3.75 & -8.61 & 15.4 \\
\hline Wind & 2.83 & 32.11 & 29.28 & $/$ \\
\hline Solar & 0 & 0 & 0.19 & -0.07 \\
\hline $\begin{array}{c}\text { Net } \\
\text { import }\end{array}$ & 4.02 & -14.12 & -18.14 & 32.4 \\
\hline Load & 67.42 & 40.5 & -26.92 & $/$ \\
\hline
\end{tabular}

As shown in Table 2, in the whole process, the coal power units, pumped storage units, gas units and transnational connection lines play an important role in balancing the load demand during peak time and promoting the consumption of wind power during valley time.

In 2019, the power grid of Germany has the capability to keep normal operation with a high proportion of new energy. The maximum output level of power sources without new energy in Germany is about $100 \mathrm{GW}$. As shown in Fig.7, the maximum load demand is about $88 \mathrm{GW}$, and the minimum load demand is about $32 \mathrm{GW}$. Without considering the power support from the transnational contact lines, the maximum output level of power sources without new energy in Germany is about 1.14 times of the maximum load demand. Under the cooperation of a large number of flexible power supply, the generation space of new energy in Germany is generally about 18 74 GW. Taking into account the support of transnational contact lines, the actual power generation space will be greater. In 2019, the maximum output level of new energy in Germany is about $50 \mathrm{GW}$, which is lower than $40 \mathrm{GW}$ for most of the time. Therefore, as long as the wind conditions are good, the proportion of wind power output can reach more than $50 \%$ at any time, or even higher.

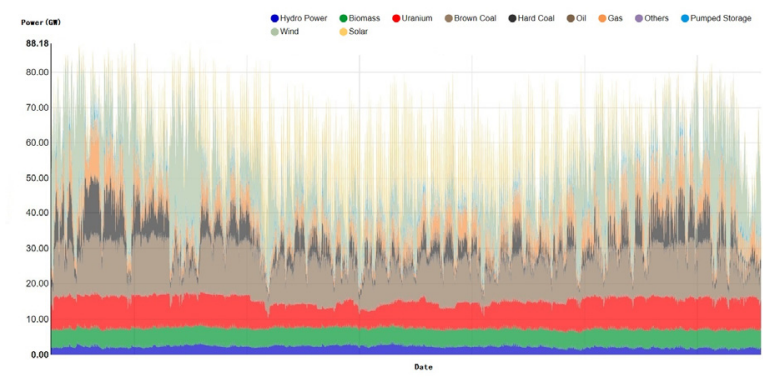

Fig. 7. Operation Curve of Power System of Germany in 2019 [1].

\subsection{Analysis of the mechanism of electricity market}

In the electricity market, market players compete with the marginal cost. New energy has an absolute advantage in market competition due to its low marginal cost of power generation. The spot market in Germany could be divided into day-ahead market and intraday market. There are two trading forms in the intraday market, including continuous bidding and collective bidding. The continuous bidding ends approximately ahead of 30 minutes before the delivery of the power product. The continuous bidding mode enables the market to respond to the volatility of new energy generation in a very short time and provides mechanism support for new energy to participate in market competition.

As shown in Fig.8, the load demand is low and the output level of new energy is high from around 9:00 a.m. on March 3 to 00:00 p.m. on March 4 in 2019. During this time period, the price in spot market is around 0 euro/(MWh), which is already significantly lower than the marginal cost of traditional power supply. Especially, 
the lowest price in spot market is -34 euro/(MWh). Therefore, the new energy can take advantage of low marginal cost to achieve priority generation in the spot market.

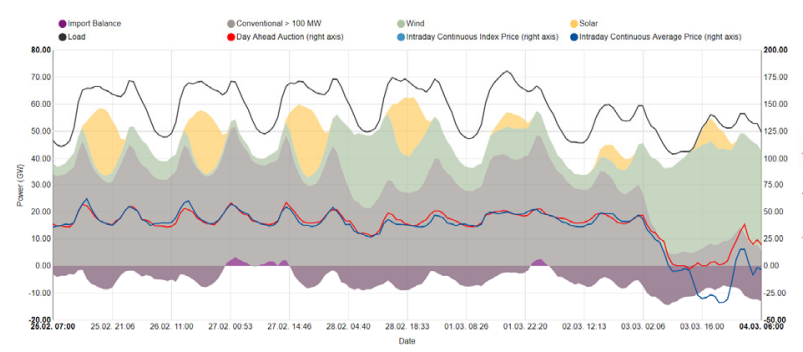

Fig. 8. Price in Spot Market from February 25 to March 4 in 2019 [1].

\section{Experience in integrating a high proportion of new energy in Germany}

Based on the analysis of the high proportion of new energy in Germany, the following characteristics can be summarized.

1) The power grid of Germany has a high abundance of power generation, and the proportion of flexible power supply and conventional power supply that can be dispatched is also relatively high. The capacity of power sources without new energy is much higher than the load demand. The system flexible adjustment power and the adjustable thermal power could deal with the fluctuation of the output of new energy in the whole year.

2) The European Interconnection grid provides a strong guarantee for Germany to cope with the volatility of new energy. The power grid of Germany is part of the European Transmission Union and the hub of the European unified grid. Almost all the countries bordering Germany have cross-border electricity deals with Germany. Transnational electricity trading can be dynamically adjusted according to the fluctuation of new energy and load demand in Germany. When the output level of new energy is high and the load demand is low, it can increase the power export and reduce the import. When the output level of new energy is low and the load demand is high, it can reduce the power export and increase the import.

3) The power grid in Germany is highly interconnected and the planning of the long-distance transmission lines is perfect. Most of the wind power in Germany is located in the northern region, which is far from the load centres in the southern and western of Germany [4]. By building the long-distance transmission lines, surplus wind power from the north could be sent to the south and west for consumption. The interconnection of grid effectively improves the ability of the power grid of Germany to allocate resources on a large scale.

4) The spot market and the price mechanism based on the operation cost have played a great role in promoting the consumption of new energy in Germany $[5,6]$. By improving the market design, Germany continuously strengthens the construction of intraday market and moves the market trading time to real-time.

\section{Conclusion}

Germany's renewable energy has developed rapidly. Germany leads the world in energy transformation, with wind and solar generating capacity accounting for nearly half. Germany's experience and practice in developing renewable energy are worthy of our country's reference. For our country, when we develop the new energy, we should build enough flexible power supply including pumped storage, improve the adjustment capacity of conventional thermal units, build interconnected power grids, and improve the spot market mechanism.

\section{Acknowledgement}

This work is supported by State Grid Corporation Science and Technology Project (SGSDJY00GPJS2000020).

\section{References}

1. https://www.energy-charts.de/index.htm

2. Agora Energiewende and Sandbag (2020), The European Power Sector in 2019: Up-to-Date Analysis on the Electricity Transition.

3. Federal Ministry for Economic Affairs and Energy, Second Progress Report on the Energy Transitionthe Energy of the Future. 2017

4. Jiansheng Tan, The Development of Clean Energy in China from the Perspective of German Energy Transformation. China Opening Journal, 3 (2017)

5. Menglei Rong, Research on the Model of the Dayahead Electricity Market Clearing Considering Renewable Energy. School of North China Electric Power University, 2019

6. Zhihong Mo, and Haixia Shi, Path Selection of Solving Wind Abandon in China_the Possibility of Introducing Negative Power Price Mechanism of Germany. Price: Theory \& Practice, 3 (2018) 